C i e n 



\section{Cubrimiento mediático de las elecciones locales de 2015 en Colombia: entre Ia opacidad política y el centralismo informativo*}

\section{Media Coverage of 2015 Local Elections in Colombia: between Political Opacity and Informative Centralism}

Juan David Cárdenas Ruiz**

Recibido: 9 de noviembre de 2015

Aprobado: 9 de febrero de 2016

Disponible en línea: 20 de diciembre de 2016

\section{Resumen}

Los medios de comunicación tienen un rol determinante en los procesos electorales. En octubre de 2015, se celebraron las elecciones para seleccionar a los mandatarios y representantes regionales y municipales en Colombia. La Misión de Observación Electoral y un grupo de universidades realizó un monitoreo al cubrimiento realizado por los principales medios de comunicación al proceso electoral. Este artículo se enfoca en los noticieros de los dos canales nacionales con mayores niveles de rating y con un posicionamiento histórico dentro de las audiencias nacionales, Caracol y RCN, analizando la agenda, los actores y las estrategias de construcción de la información en busca de plantear una serie de reflexiones en torno al rol de los medios en el cubrimiento de procesos electorales

\section{Abstract}

Mass media have a central role in electoral processes. In October 2015 local elections were held to select regional and local representatives and executive authorities in Colombia. The Mission for Electoral Observation (MOE) and a group of national universities made a monitoring excercise to the mainstream media coverage of elections. This article focuses on the news magazines of the two main television channels in Colombia with the highest rating and historic audience analyzing the agenda, social and political actors, and strategies of information construction seeking to raise some reflections about the role of the media in covering electoral processes in Colombia. The article shows two trends of this coverage. First, excessive centralism in the information coverage, and second,

doi: 10.11144/Javeriana.papo21-2.cmel

* Artículo de investigación.

** Universidad de La Sabana (Chía, Colombia). Correo electrónico: juancar@unisabana.edu.co 
en Colombia. En el artículo, se evidencian dos tendencias de este cubrimiento. Primero, el excesivo centralismo en el cubrimiento de la información; y segundo, la falta de transparencia y equilibrio informativo, en la medida en que los medios asumen agendas políticas e ideológicas defendiendo posiciones e intereses políticos determinados.

\section{Palabras clave}

elecciones; medios de comunicación; televisión; agenda setting; framing

\section{Cómo citar este artículo:}

Cárdenas-Ruiz, J. D. (2016). Cubrimiento mediático de las elecciones locales de 2015 en Colombia: entre la opacidad política y el centralismo informativo. Papel Político, 21(2), 319-342. https://doi.org/10.11144/Javeriana. papo21-2.cmel lack of transparency and informational balance, insofar as the media assume political and ideological agendas defending determined political positions and interests.

\section{Keywords}

elections; mass media; television; agenda setting; framing 


\section{Introducción}

Los procesos electorales son parte esencial de la democracia contemporánea. La expresión institucionalizada de la voluntad popular es un requisito ineludible de todo sistema político democrático. La calidad de la democracia se ve, en parte, determinada por la transparencia, la libertad y la vitalidad de las elecciones que deben ser un reflejo de la diversidad ideológica de una sociedad, cuyos procedimientos deben garantizar la participación y representación política de toda la sociedad involucrada. Esto lo recalcan Lange y Ward (2004) al afirmar: "Las elecciones son uno de los instrumentos centrales empleados por los Estados para asegurar que los derechos democráticos de los ciudadanos y la voluntad popular sean canalizados hacia los procesos de toma de decisiones" (p. 10).

En este proceso, los medios de comunicación son actores fundamentales de la construcción social de la realidad en torno al proceso electoral. Por sus lentes, páginas y ondas, circula la información que da sentido a la realidad de campaña, en este caso, los problemas políticos y sociales, los atributos de los candidatos y sus defectos, entre otros aspectos.

Lange y Ward (2004) aseguran:

Los medios masivos son un componente crucial en el proceso de diseminación de noticias y comentarios, junto con la naturaleza de esta información, son cruciales para tener estructuras de gobierno sostenibles y fiscalizables. Los medios son instrumentales para el proceso y la plataforma que proveen en tiempo de elecciones permanece como un escenario vital para la presentación de las ideologías de los partidos, así como para garantizar al público la oportunidad de escrutar y recolectar información de un amplio espectro de propuestas presentadas por los candidatos. (p. 10)

Con 32 departamentos, más de 1100 municipios, cada uno con sus respectivas autoridades ejecutivas y legislativas, las elecciones locales convocan periódicamente a millones de colombianos a las urnas. En el mes de octubre de 2015, se celebraron las más recientes elecciones de autoridades locales del país con la participación de más de 20 millones de electores, lo cual representa $59.44 \%$ del censo electoral de potenciales sufragantes. ${ }^{1}$

Estas elecciones representan un escenario donde hay muchas cosas importantes en juego desde el punto de vista del poder político, el acceso al presupuesto público y la consolidación o transformación de proyectos políticos, en algunos casos hegemónicos, y en otros, más coyunturales en las ciudades y regiones del país.

Siendo Colombia un país de ciudades, donde se encuentran al menos 10 municipios de más de 500 ooo habitantes, y 30 municipios de más de 100 ooo habitantes, las

${ }^{1}$ Según información oficial de la página web de la Registraduría General del Estado Civil. 
elecciones locales no son un proceso electoral cualquiera. Esa misma composición, que marca un fuerte regionalismo, históricamente ha configurado élites políticas que han consolidado un dominio político, en algunos casos hegemónicos; en otros, competidos, y en otros en alianza o en abierta confrontación con actores ilegales, como los grupos guerrilleros, grupos paramilitares y carteles del narcotráfico.

Ante un escenario tan convulsionado y dinámico, los medios de comunicación se aproximan de distintas maneras al proceso electoral. Cabe recordar que el sistema de medios colombiano está segmentado territorialmente entre medios de carácter nacional, regional y local, teniendo cada medio una influencia particular en su área más cercana.

Según World Value Survey, oleada 2014, la principal fuente de información de 87 \% los colombianos es la televisión. Según el estudio general de medios EGM de noviembre de 2015, la penetración de la televisión en la sociedad colombiana es de 88 \%.

En este contexto, si bien deben competir o coexistir con sistemas de cable y servicios de entretenimiento digitales por demanda, en el rubro de la información política, los noticieros nacionales siguen teniendo la primacía dentro de los hábitos de consumo de la audiencia colombiana, especialmente los noticieros de los dos canales privados de mayor rating, Caracol y RCN, y con mayor nivel de audiencia en el horario de las 7:00 p. m., su edición central de noticias.

Teniendo difusión y presencia nacional, estos dos canales y sus noticieros constituyen una referencia informativa obligada en los procesos electorales con una mayor o menor influencia en las regiones del país, cada una de ellas con sus propios medios de alcance regional o local. Caracol y RCN pertenecen, cada uno, a grandes grupos empresariales que no solo están presentes en el negocio de los medios de comunicación.

\section{Metodología}

La Misión de Observación Electoral ${ }^{2}$ viene adelantando desde 2007 un ejercicio de monitoreo al cubrimiento que los medios de comunicación hacen de los procesos electorales en Colombia a través de una plataforma de universidades públicas y privadas de la cual hace parte la Universidad de La Sabana a través del grupo de investigación del Observatorio de Medios de la Facultad de Comunicación.

Para el proceso de elecciones locales de 2015, el Observatorio de Medios, en alianza con el Seminario de Investigación en Comunicación Pública, ${ }^{3}$ realizó el monitoreo a los noticieros de los dos principales canales de televisión de Colombia: Noticias RCN y Caracol Noticias.

\footnotetext{
2 Plataforma de organizaciones de la sociedad civil, independiente del Gobierno, de los partidos políticos y de intereses privados, que promueve la realización del derecho que tiene todo ciudadano a participar en la conformación, ejercicio y control del poder político.

${ }^{3}$ Seminario de profundización en investigación de fenómenos de comunicación pública.
} 
El ejercicio de monitoreo permitió establecer cuáles fueron las estrategias de construcción de la información (agenda setting) y las fuentes informativas que fundamentaban las agendas, tras lo cual se llegó a unos hallazgos que revelan ciertos parámetros estructurales que caracterizan los cubrimientos mediáticos desde espacios noticiosos nacionales, como el centralismo informativo, el desequilibrio de género y la construcción intencionada de agendas temáticas.

Fueron analizadas las emisiones de noticias de las siete de la noche de lunes a viernes de los noticieros mencionados. ${ }^{4}$ Se identificaron 113 notas para Noticias RCN y 135 notas para Noticias Caracol relacionadas con el proceso electoral. El periodo de observación inició el 25 de julio y se adelantó hasta una semana después de culminado el proceso electoral.

El análisis de las notas se llevó a cabo por equipos de observadores que diligenciaban la información, posteriormente a una capacitación y prueba piloto, en una matriz diseñada por la Misión de Observación Electoral con variables prestablecidas y conceptualizadas. Este artículo presenta los resultados del análisis y plantea una discusión sobre el efecto que pueden tener estas estrategias de cubrimiento de los procesos electorales desde noticieros de cobertura nacional.

\section{Medios de comunicación y procesos electorales}

Los medios de comunicación son actores centrales de los procesos electorales. Entre sus funciones, están servir de canal de comunicación de las propuestas de los candidatos hacia el electorado, visibilizar las problemáticas nacionales, regionales y locales, dar visibilidad a los distintos sectores sociales, económicos y políticos en el territorio, servir de elemento educativo y pedagógico electoral en contextos de baja cultura política participativa, entre otros.

Cualquier análisis del papel de los medios de comunicación en los procesos electorales debe partir de asumir estos como actores políticos que hacen parte de la contienda y defienden intereses políticos, ideológicos, de manera implícita o explícita. Independiente de esta realidad, en la mayoría de los casos "oculta” o ignorada, los medios de comunicación tienen una responsabilidad social con el sistema político y social al ser los principales vehículos de transmisión de información para la toma de decisiones de los ciudadanos en las instancias electorales.

Esta labor, desde una perspectiva del deber ser, debería guiarse por dos principios rectores de toda actividad informativa en escenarios políticos: 1 . el equilibrio informativo y 2. el pluralismo político. Los medios de comunicación de carácter privado, como principales fuentes de información, especialmente en la televisión, deberían brindar

${ }^{4}$ Dentro del ejercicio de monitoreo realizado por la plataforma de universidades se hizo la observación de medios de carácter regional: Telecafé Noticias, Teleantioquia Noticias, TeleMedellín y Hora 13. 
espacios para que los ciudadanos conozcan a todos los candidatos y sus propuestas con suficiencia (equilibrio informativo). El electorado debe conocer y comprender la diversidad política e ideológica a la cual se enfrenta a la hora de encarar un proceso electoral (pluralismo político).

El centro del debate es cuestionar hasta qué punto la comunicación política a través de los medios masivos puede y quiere cumplir con estos criterios. En este caso, donde la televisión persiste aún como el principal medio de comunicación en escenarios de campaña electoral, en un contexto de cultura política de baja participación política y altos índices de consumo de medios, la televisión tiene una influencia importante en los procesos electorales en el ámbito nacional, regional y local como referente informativo y de construcción social de la realidad a través de distintos géneros informativos y en diferentes niveles de encuadre de la realidad a través de sus líneas editoriales, producción noticiosa e influencia de los líderes de opinión.

\section{Televisión, comunicación política y campañas electorales}

Si bien la euforia de la revolución de las tecnologías de la información y los nuevos medios de comunicación ha orientado la atención hacia el impacto de internet y las redes sociales sobre distintos aspectos de la sociedad, la televisión sigue siendo el medio de comunicación más consumido por las personas y donde los actores políticos siguen enfocando gran parte de sus estrategias, no solo por su penetración masiva, sino también porque es un medio tradicional para la comunicación política, cuyos espacios y formatos están muy arraigados dentro de la cultura política tradicional de los países latinoamericanos.

Martínez Pandiani (2014) afirma:

La TV constituye una fuente primordial de información en el momento de buscar respuestas a las preguntas, que, como ciudadanos, se plantean. Ante la necesidad de evaluar opciones políticas y tomar decisiones electorales, se observa en los votantes una clara tendencia a recurrir a los medios masivos de comunicación (en especial la televisión) en lugar de dirigirse a comités u otras organizaciones partidarias. (p. 70)

La televisión se ha constituido, por su alcance masivo, y la adaptación comunicativa a las audiencias, en una fuente primordial de información política, no necesariamente de la mejor calidad, pero sí la que está más cerca del ciudadano del común que aún no está inmerso en el mundo de la política 2.o. Johnson-Cartee (2004) señala:

Debe anotarse que los individuos recurren a las noticias en TV no solo en búsqueda de información fáctica sino también para tener guías de evaluación. La televisión va más allá del simple establecimiento de agendas personales y públicas e impulsa la creación de dimensiones evaluativas de los discursos públicos. (p. 23) 
Estas dimensiones evaluativas son más comúnmente conceptualizadas comoframes o marcos de interpretación. Goffman (1986), refiriéndose al efecto del framing, afirmaba que los individuos que no pueden entender enteramente el mundo luchan constantemente para interpretar sus experiencias vitales y tratar de dar sentido al mundo que los rodea, y con el propósito de hacer un procesamiento de información más eficiente, aplican esquemas o marcos interpretativos para clasificar la información e interpretarla significativamente. Estos marcos de interpretación desde el punto de vista macro estarían influenciados por la forma en como los medios y sus periodistas presentan la realidad de tal manera que resuenen con los esquemas subyacentes de sus audiencias.

Scheufele y Tewksbury (2007, pp. 12-15) determinan tres dimensiones en las que el framing es visible y se vuelve objeto de análisis: 1. producción de las noticias, 2. procesamiento de las noticias y 3. sus efectos cognitivos. En el primer caso, afirman que los frames son construidos intencionalmente en los procesos de producción informativo y obedecen a intereses puntuales de medios y periodistas. En el segundo caso, se sostiene que, si bien pueden existir frames, estos dependen más de la forma en que las audiencias interpretan las noticias, lo cual depende, en gran medida, del conocimiento y el nivel de atención de los espectadores. Finalmente, el efecto cognitivo, ligado a una dimensión psicológica, lo que sostendría es que el efecto framing tendría un efecto a partir de los issues o etiquetas que se utilicen para la comunicación de un asunto público.

Dentro de este escenario del framing, se desprende otro fenómeno que evidencia una relación transformativa entre televisión y comunicación política. Berrocal (2004) sostiene:

La televisión tiene un indudable poder determinando qué noticias, qué asuntos y, en especial, qué candidatos deben recibir una cobertura diaria. La política televisada atrae audiencias como ningún otro medio, es el soporte fundamental de la información política y consigue introducir en los hogares de los ciudadanos, con escaso tiempo, las imágenes de los aspirantes en la carrera política. De ahí, que con independencia del sistema electoral y de partidos de que se trate, la televisión sitúa al líder en el centro de la comunicación política. (p. 56)

Ante la apatía política, la falta de intereses y la desconfianza de los ciudadanos hacia la clase política, las rutinas informativas relacionadas con la información política han devenido la personalización, banalización y espectacularización de los asuntos públicos. En este escenario, el tipo de comunicación política que activa la televisión ha sido fundamental. Al respecto, Dader (1998) manifiesta:

La confluencia de la componente teatral de la política con la expresividad dramática del relato periodístico se refuerza entonces entre sí y abocan con facilidad al ejercicio de una mera función de entretenimiento de los miembros del público, en cierto modo ya apeados de su 
auténtica condición de ciudadanos. En primer lugar, porque toda información adquirida sin ánimo de actuar o aplicarla de algún modo denota ya una actitud contemplativa y cercana al concepto de entretenimiento (la propia palabra de espectador refleja una ausencia de implicación y por tanto propende a eliminar todo lo que suponga esfuerzo físico o intelectivo). En segundo lugar porque las condiciones de rentabilidad masiva que han de reunir los productos periodísticos - aun cuando versen sobre cuestiones aparentemente serias como el interés general y la política-, contribuyen a primar una selección de contenidos y tratamientos especialmente amenos o por lo menos apelativos sin el mínimo esfuerzo perceptivo (un asesinato o un acto terrorista, junto a la angustia que provoca, actúa como una película de miedo: es desagradable pero desata emociones sin esfuerzo, luego consciente o inconscientemente para su espectador lejano y en realidad no afectado, no deja de suponerle otro tipo de espectáculo liberador de emociones). En tercer y último lugar porque la recepción y contexto de esas versiones periodísticas de las manifestaciones de los implicados directamente en la política llegan al público o consumidor (sólo formalmente ciudadano) en el tiempo dedicado al ocio o tiempo libre y por eso mismo desactivadas ya de su potencial de provocar otro tipo de funciones ajenas al ámbito del entretenimiento. (p. 125)

Semetkho (2007), en la misma dirección, sostiene: “Cada vez se preocupan menos por temas y asuntos políticos y cada vez ponen más atención sobre la personalidad y las calidades individuales de los líderes políticos y sus opciones electorales” (pp. 124-125).

La política, en general, y las elecciones, específicamente, en sociedades con cultura política de baja participación, desconfianza ciudadana hacia las instituciones y altos índices de corrupción, pareciera ser interesante para los ciudadanos solo en la medida en que pueda llamar su atención desde el formato informativo en que es llevada por los medios. Esto, inevitablemente, tiene un impacto en la labor de los medios, en las estrategias de campaña de los candidatos y en las expectativas informativas de los ciudadanos, sobre todo cuando los formatos mediáticos, las nuevas tecnologías y la entrada de las redes sociales generan nuevos espacios, lenguajes y dinámicas de comportamiento social frente a los fenómenos políticos, como las elecciones. Se espera, en ese orden de ideas, que la televisión y los noticieros incorporen esas nuevas herramientas y posibilidades para llevar las elecciones a esos ciudadanos con nuevas expectativas, entre ellas, un mayor acercamiento del medio a sus problemas cotidianos, la posibilidad de ser fuente informativa y, en general, a que exista mayor margen de participación ciudadana en la construcción de la agenda política e informativa.

\section{La influencia de la televisión en los procesos electorales}

El papel de los medios de comunicación en los procesos electorales es un tema de investigación de vieja data. Desde distintas perspectivas se ha buscado establecer cuál es 
el efecto que puede llegar a tener la cobertura de los distintos medios sobre las decisiones de los ciudadanos y las estrategias de las campañas electorales. Strömbäck y Kaid (2008) realizan, junto con otros autores, un estudio comparativo exhaustivo de cómo, en distintos contextos, los medios influyen sobre los procesos electorales:

\begin{abstract}
La importancia del cubrimiento mediático de las elecciones democráticas se origina por el simple hecho de que las personas, en su mayoría, acuden a los medios para informarse y poder tener más criterios para sus decisiones. Los medios, entonces, tienen un enorme poder en relación con los temas, atributos y marcos de interpretación que pueden ser considerados importantes y relevantes. ${ }^{5}$ (p. 13)
\end{abstract}

Las elecciones deben verse como un proceso que trasciende lo netamente partidista/ institucional. En este proceso, los medios de comunicación son uno de muchos actores más que hacen presencia e influyen sobre su desarrollo. Al respecto, Gulati, Just y Crigler (2004) sostienen:

Las noticias sobre las campañas políticas representan una negociación permanente entre actores centrales del proceso de campaña: del lado de los medios: periodistas, editores y propietarios. Del lado de las campañas: candidatos, staff de campaña y activistas de partido. Del lado del "público": instituciones gubernamentales, grupos de interés y expertos. Todos desempeñan un papel dentro del proceso de creación de noticias. (p. 237)

Dentro de esta construcción de los marcos de interpretación, es útil volver sobre los conceptos de frames temáticos y frames episódicos planteados por Inyegar (1994). Benjamin (2007), referenciando a Inyegar, define los frames temáticos como "aquellos donde a un tema se le da un ángulo amplio enfocándose en su tendencia sobre el tiempo, explicando su contexto y ambiente". Los frames episódicos serían aquellos donde "un tema es enfocado a partir de una persona o evento específico". Las diferencias más marcadas entre los dos tipos de frames se muestran a continuación (tabla 1).

\footnotetext{
${ }^{5}$ Las traducciones son mías.
} 
Tabla 1. Frames temáticos y episódicos

\begin{tabular}{|l|l|}
\hline \multicolumn{1}{|c|}{ Frames temáticos } & \multicolumn{1}{c|}{ Frames episódicos } \\
\hline $\begin{array}{l}\text { Se enfocan sobre los individuos protagonistas } \\
\text { de un hecho }\end{array}$ & Se enfoca sobre los issues \\
\hline Se enfocan sobre eventos/episodios aislados & $\begin{array}{l}\text { Se enfoca sobre tendencias, contextos, } \\
\text { ambientes }\end{array}$ \\
\hline $\begin{array}{l}\text { Se enfocan, principalmente, sobre el ámbito } \\
\text { privado }\end{array}$ & $\begin{array}{l}\text { Se enfocan, principalmente, sobre el ámbito } \\
\text { de lo público }\end{array}$ \\
\hline $\begin{array}{l}\text { Personas que experimentan situaciones y } \\
\text { cómo solucionarlas }\end{array}$ & $\begin{array}{l}\text { Condiciones que llevan a surgir problemas y } \\
\text { como solucionarlo }\end{array}$ \\
\hline Audiencia como consumidor & Audiencia como ciudadano \\
\hline $\begin{array}{l}\text { La solución se muestra como una mejor } \\
\text { información }\end{array}$ & La solución se muestra como mejores políticas \\
\hline
\end{tabular}

Fuente: Adaptado de Benjamin (2007).

La construcción de los marcos de interpretación desde esta perspectiva puede marcar una dirección hacia información racional (temática) o información emocional (episódica), lo cual implica una reacción similar en la toma de decisiones de los ciudadanos mediada por los estímulos e impulsos que estos mismos reciben de los medios.

Los procesos electorales son influenciados por la televisión en dos direcciones distintas. La primera de ellas se refiere a cómo las campañas deben adaptarse al entorno mediático, comunicativo, que impone la televisión respecto de los mensajes, los tiempos, los targets y las estrategias de comunicación. La segunda se refiere a la forma en cómo los medios construyen la realidad de la campaña a partir de su producción informativa y cómo esta opera como un filtro de selección de personas, posiciones, temas y evaluaciones de la realidad.

Grabe (2009) señala:

Las elecciones contemporáneas están construidas sobre bases visuales. Los candidatos deben aparentar ser lo suficientemente telegénicos para invitar y mantener un escrutinio más cercano, y sus eventos de campaña, para ser efectivos, deben fortalecer y reforzar la imagen del candidato y sus iniciativas políticas. Desde la aparición de la televisión como una fuerza política, la imagen de los candidatos ha sido construida visualmente a través de estrategias diseñadas para promover cualidades deseadas y temas predilectos. El enfoque visual permite diferentes niveles de intimidad entre el candidato y la audiencia, subrayar atributos de los candidatos y tener imágenes estratégicas que afecten el apoyo electoral. (p. 102)

La televisión marcó el tránsito de una lógica de campaña en terreno, desgastante, de constante dinámica, comunicativamente enfocada en el candidato como principal emisor del mensaje a través de los medios existentes, a una campaña masiva, donde el poder de 
la imagen y la facilidad de alcanzar numerosas audiencias sin el problema de los obstáculos geográficos que impedían la "omnipresencia” del candidato.

Strömbäck (2008) sugiere tres etapas históricas que se corresponden con tres tipos de campañas electorales, y a su vez con tres tipos distintos de comunicación política. Sostiene que existen campañas premodernas, modernas y posmodernas (tabla 2).

Tabla 2. Tipos de prácticas de campañas electorales

\begin{tabular}{|l|l|l|l|}
\hline $\begin{array}{l}\text { Tipo de } \\
\text { campaña }\end{array}$ & \multicolumn{1}{|c|}{ Premoderna } & \multicolumn{1}{|c|}{ Moderna } & \multicolumn{1}{c|}{ Posmoderna } \\
\hline $\begin{array}{l}\text { Modo de comunicación } \\
\text { política }\end{array}$ & Partidista & Centrada en la TV & $\begin{array}{l}\text { Múltiples canales y } \\
\text { medios }\end{array}$ \\
\hline $\begin{array}{l}\text { Estilo dominante de } \\
\text { comunicación política }\end{array}$ & $\begin{array}{l}\text { Mensajes entre } \\
\text { miembros del partido }\end{array}$ & $\begin{array}{l}\text { Imágenes, sonidos, } \\
\text { manejo estratégico } \\
\text { visual }\end{array}$ & $\begin{array}{l}\text { Targets, mensajes } \\
\text { específicos, } \\
\text { segmentación }\end{array}$ \\
\hline Medios & $\begin{array}{l}\text { Radio, prensa, medios } \\
\text { partidistas }\end{array}$ & Televisión & $\begin{array}{l}\text { Televisión, internet, } \\
\text { redes sociales }\end{array}$ \\
\hline $\begin{array}{l}\text { Medios publicitarios } \\
\text { dominantes }\end{array}$ & Impresos & Avisos en TV & $\begin{array}{l}\text { Anuncios, correos, } \\
\text { mensajes de texto }\end{array}$ \\
\hline $\begin{array}{l}\text { Coordinación de } \\
\text { campaña }\end{array}$ & Líderes partidistas & $\begin{array}{l}\text { Líderes partidistas y } \\
\text { expertos en medios }\end{array}$ & $\begin{array}{l}\text { Líderes partidistas y } \\
\text { consultores políticos }\end{array}$ \\
\hline $\begin{array}{l}\text { Paradigma dominante } \\
\text { de campaña }\end{array}$ & Partidista & Mediático & Mercadotécnico \\
\hline Presupuesto & Bajo & Creciente & Creciente \\
\hline Electorado & Clivajes, grupos sociales & Volátil, erosionado & $\begin{array}{l}\text { Alta volatilidad y } \\
\text { comportamiento basado } \\
\text { en issues }\end{array}$ \\
\hline
\end{tabular}

Fuente: Adaptado de Strömbäck (2008, p. 52).

La mediatización progresiva de los procesos electorales afecta directamente la manera en que se construyen las estrategias de campaña. Los partidos y candidatos deben adaptarse al nuevo ecosistema mediático, en el que, a pesar del crecimiento exorbitante de las redes sociales, la televisión sigue ocupando un lugar privilegiado dentro de las campañas políticas. Es en este contexto donde el marketing político entra a ocupar un lugar dentro de la normalidad de las campañas. Bien lo afirma Martínez Pandian (2014) cuando sostiene que la televisión tiene un impacto sobre la política al estimular su mediatización, personalización, espectacularización, audiovisualización y marquetinización.

En esa misma dirección, Boix y Stokes (2009) afirman que es importante analizar los procesos electorales a la luz de los contextos culturales, educativos y tecnológicos. Al respecto, señalan: "Cuanto más los partidos dejan de ser referentes informativos importantes, la política ha empezado a estar más centrada en los candidatos y las campañas menos basadas en maquinarias partidistas" (p. 15).

Algunos teóricos llaman este proceso la "profesionalización” o "americanización” de las campañas políticas (Schmitt-Beck, 2009; Holtz-Bacha, 2002; Gibson y Römmele, 2001; Mancini y Swanson, 1996). Schmit-Beck señala: 
Las campañas americanizadas son conducidas principalmente a través de los medios masivos. La publicidad pagada en televisión es el canal dominante para las comunicaciones de campaña, casi equivalente a grandes cantidades de noticias y programas de asuntos públicos. Las organizaciones de campaña consideran también muy importantes los contenidos regulares de los medios de comunicación y buscan instrumentalizar las noticias a su favor. (p. 747)

Dentro de este concepto de la americanización, autores como Holtz-Bacha (2002) hacen hincapiñe en la "despolitización" como un factor para comprender las campañas electorales. La televisión vendría a ser un factor central de esa despolitización a través de un fenomeno mencionado anteriormente: la personalización. Al respecto, indica:

La despolitización, entendida como la desaparación de los issues, es una estrategia de campaña desde la perspectiva de los actores políticos y sus equipos de campaña. Esta evita la polarización ideológica que deja de ser importante para el electorado. Para los políticos, es más conveniente no asumir compromisos fuertes durante la campaña. La personalización estimula los asuntos políticos abtsractos, sobre todo en TV, haciéndolos más simples y atractivos. Más que mostrar posiciones sobre temas, las diferencias entre partidos se construyen sobre la base de candidatos o la presentación de equipos de políticos. La personalización va de la mano de las estrategias de imagen y la posible privatización de la política, es decir, la presentación de los candidatos en roles privados y en ambientes personales privados antes que en su faceta de políticos. (p. 27)

Craig (2000, p. 29) sostiene que los medios presentan las campañas como "una serie, día a día de eventos existosos o fallidos basados en las posiciones de las encuestas y la respuesta de los candidatos frente a estos episodios”. De igual manera señala:

Convirtiendo la campaña en una serie diaria de victorias y derrotas, los medios bien podrían llevar a los votantes a relacionar la viabilidad o competencia de un candidato con su habilidad de campaña y, entonces, determinar que el que mejor campaña realiza puede ser el mejor para ocupar el cargo. (p. 29)

Los efectos de las noticias en TV, como se observa, son variables de acuerdo con el tipo de información que se transmite y el enfoque que se le da a la contienda. El énfasis sobre encuestas genera la sensación de una "carrera de caballos" o una competencia ciclistica con altas y bajas. El énfasis sobre episodios personales genera una contexto melodramático con expetcativas emocionales de los ciudadanos frente a la información que se espera. El énfasis en los eventos negativos, como delitos electorales, fraudes y demas prñacticas corruptas, puede desincentivar, aún más, el interés ciudadano frente a la 
participación política. El énfasis en las conforntaciones entre candidatos, debates e issues temáticos generaría un entorno informativo más racional para la toma de decisiones.

Como se puede ver, el impacto de la televisión sobre los procesos electorales ha sido variable, en el sentido en que afecta diferencialmente a todos los actores involucrados. Desde lo medios se ven transformaciones en los procesos de construcción informativa de la realidad, enmarcamiento y construcción de agendas. En los candidatos, se observan transformaciones en sus estrategias discursivas y de imagen. Y en los ciudadanos se evidencia una necesidad de mayor información, no necesariamente con la calidad y profundidad necesaria, pero sí la existencia de mayor cantidad de esta, orientada más desde lo emocional, que deja de lado los temas (issues) racionales que deben ser lo más relevantes en una campaña electoral.

\section{Resultados}

El ejercicio de monitoreo al cubrimiento mediático del proceso electoral adelantado por la Misión de Observación Electoral en convenio con un grupo de universidades colombianas se enfoca en las agendas, los actores y el equilibrio informativo en la construcción mediática del escenario electoral. Como ya se ha mencionado, los medios de comunicación, y en este caso los dos canales de televisión de alcance nacional, tienen un gran poder a la hora de dar visibilidad a ciertas temáticas y actores políticos y sociales en las elecciones. A continuación, se presentan los principales hallazgos de la observación al cubrimiento mediático de las elecciones realizado por Noticias Caracol y Noticias RCN en las elecciones locales de octubre de 2015 en Colombia.

\section{La agenda de las elecciones}

El monitoreo trató de identificar, en primera instancia, cuáles eran los temas que estructuraban la agenda de ambos espacios noticiosos. Se encuentra una primera diferencia interesante. Si bien el tema predominante en ambos noticieros son todos los hechos relacionados con el proceso electoral, hay una diferencia de casi treinta puntos porcentuales entre Caracol Noticias (91 \%) y RCN Noticias (66 \%) (figura 1).

\section{Figura 1. Agenda temática Noticias Caracol.}

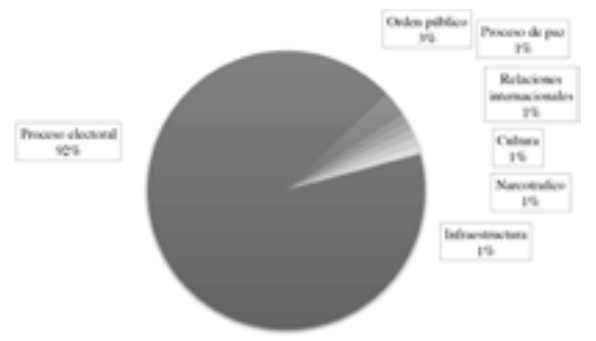

Fuente: elaboración propia 
Los temas que complementan la agenda en el caso de Caracol son orden público y en menor medida cultura, narcotráfico, infraestructura, proceso de paz, situación social y relaciones internacionales (figura 2).

\section{Figura 2. Agenda temática Noticias RCN.}

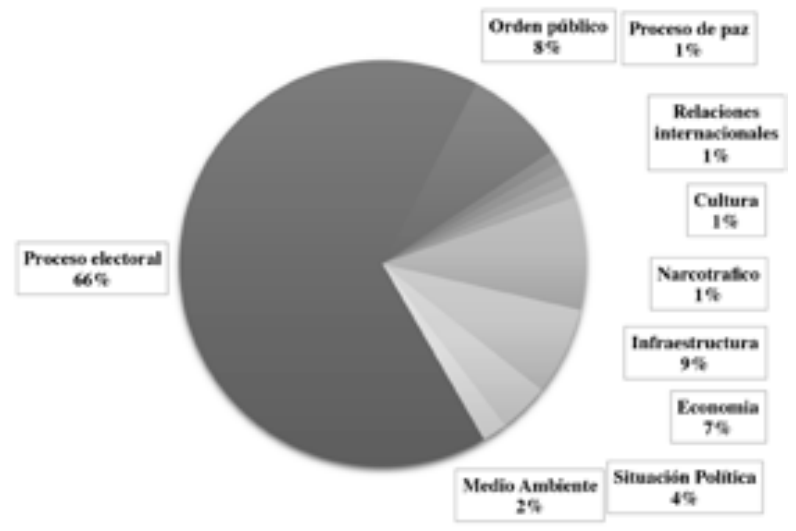

Fuente: eElaboración propia

Dentro de la categoría proceso electoral, metodológicamente se habían predefinido subtemas que podrían aparecer en el cubrimiento mediático al proceso electoral (figuras 2 y 3). Estos temas están relacionados con eventos o situaciones "estructurales" de todo proceso electoral relacionados con los procedimientos y las circunstancias normales de un proceso de esta naturaleza, como los debates, la publicidad política, las encuestas, entre otros. Por otra parte, elementos más ligados a prácticas “informales”, como los delitos electorales, la presión al ejercicio electoral, el acento sobre la vida privada de los candidatos y su trayectoria.

El objetivo de esta clasificación era trascender el nivel superficial, obvio, de simple verificación de que los temas electorales son los más preponderantes en época de elecciones. $\mathrm{Al}$ respecto, se encuentra que existen cuatro temas principales frente a los cuales gira, mayoritariamente, la construcción mediática del proceso electoral por parte de Noticias Caracol y Noticias RCN.

Los delitos electorales, el proselitismo político, los resultados de las elecciones y las encuestas son los cuatro temas centrales del cubrimiento electoral de ambos medios.

Para el caso de Noticias Caracol (figura 3), los dos temas principales son los delitos electorales y el proselitismo electoral. Otros temas relevantes, junto con los resultados y las encuestas, son los relacionados con los avales/alianzas, la vida privada del candidato, e investigaciones a candidatos/funcionarios. 
Figura 3. Subtemas proceso electoral (Noticias Caracol).

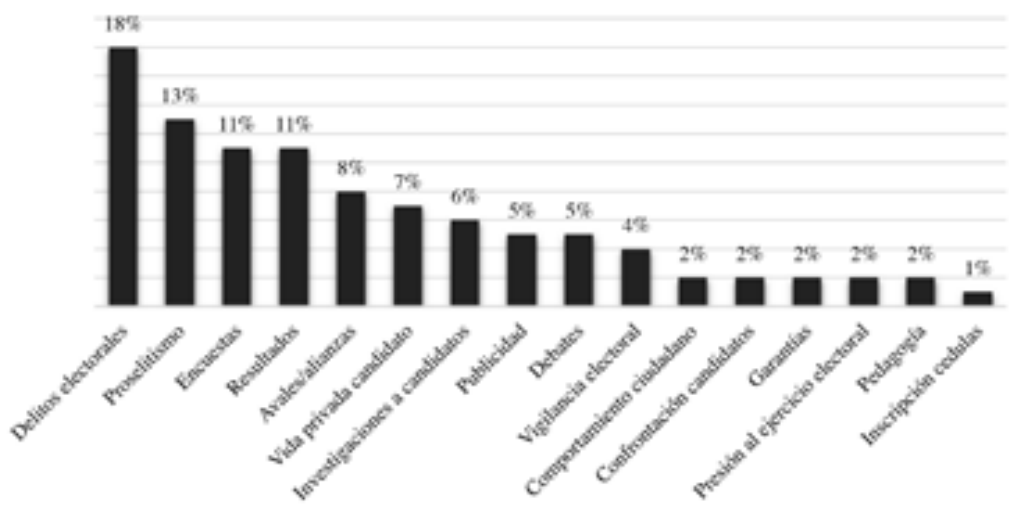

Fuente: elaboración propia

Podría afirmarse que el cubrimiento de Noticias Caracol está orientado a la búsqueda de un proceso electoral transparente, al menos desde la dimensión informativa. Aspectos como los debates y las confrontaciones entre candidatos no aparecen en un primer plano, con lo cual relegan la agenda política temática a un segundo plano frente a aspectos más informativos, procedimentales del proceso.

Para el caso de Noticias RCN (figura 4), los dos temas principales son los resultados de las elecciones y de las encuestas, seguidos de delitos electorales y proselitismo electoral. Se evidencia una labor más reactiva del medio orientada por resultados estadísticos en busca de una interpretación de la realidad a partir de los ejercicios de investigación de opinión pública y los mismos resultados de la elección.

Figura 4. Subtemas proceso electoral (Noticias RCN).

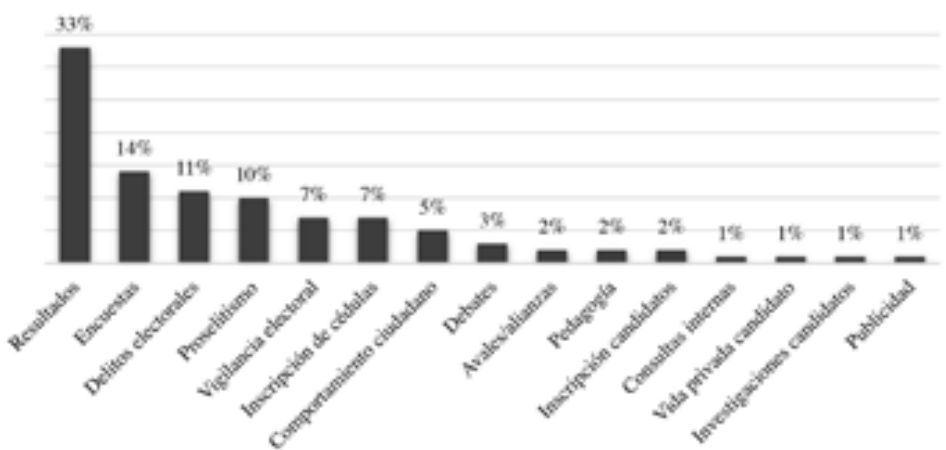

Fuente: elaboración propia 
Si bien RCN y Caracol implementan estrategias de seguimiento en campo del proceso electoral, se ve que la información en estudio, fruto de estudios e investigaciones, sigue primando sobre la agenda local, salvo que aparezca algún acontecimiento relacionado con hechos del proceso que impliquen alguna disrupción a su normalidad, como delitos electorales, la labor de la vigilancia electoral, conflictos con inscripciones de cédulas, entre otros.

\section{El equilibrio informativo en la agenda mediática}

Luego de indagar sobre los elementos temáticos de la agenda, se buscó determinar los actores que participaban o eran tomados como fuentes informativas en la construcción informativa de la realidad relacionada con el proceso electoral.

Es acá donde se da un primer hallazgo interesante, en el que tiene mucho que ver la incorporación de nuevos formatos y tecnologías de la información y la comunicación al cubrimiento mediático del proceso electoral. Las elecciones dejan de ser un escenario donde predominan los actores políticos (figura 5).

La sociedad civil es la principal fuente informativa de ambos medios. En $67 \%$ de las notas de Noticias RCN y en 49 \% de las notas de Caracol Noticias, aparecen ciudadanos como fuentes informativas.

Las autoridades gubernamentales, en correspondencia con algunos de los temas centrales de la agenda, más ligados al procedimiento electoral que al trasfondo político, aparecen como segunda fuente informativa. En Caracol Noticias, 32 \% y en Noticias RCN $26 \%$ son fuentes gubernamentales. Los partidos políticos y candidatos aparecen solo como tercera fuente informativa con $16 \%$ en Caracol Noticias y solo en $2 \%$ de las notas de Noticias RCN.

Un resultado interesante tiene que ver con la baja presencia de fuentes militares, actores otrora muy comunes dentro de este tipo de escenarios. Solo en 3 y 5 \% de las notas de Noticias Caracol y Noticias RCN aparece la fuerza pública como fuente informativa. Esto se corresponde con la relativa tranquilidad con la que se adelantó el proceso electoral de 2015 .

\section{Figura 5. Actores del cubrimiento mediático.}

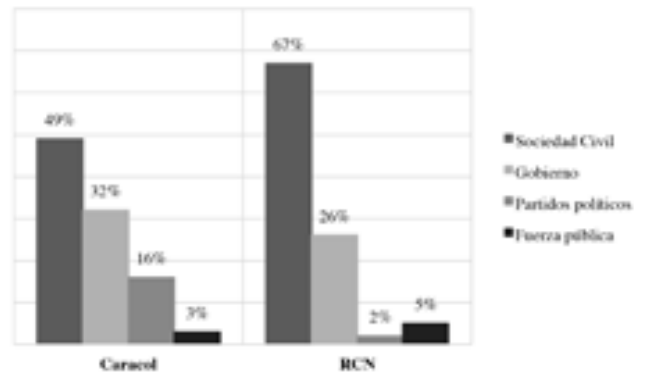

Fuente: elaboración propia 
Otro elemento que se buscó indagar, y que muestra resultados preocupantes, tiene que ver con el equilibrio informativo respecto de la equidad de género y la proporcionalidad territorial del cubrimiento, en este caso de canales nacionales, que deberían dar cuenta del proceso electoral desde una perspectiva global nacional integral.

En relación con la perspectiva de género, es necesario recordar que los resultados reflejan patrones de la cultura política nacional y que no obedecen exclusivamente a prácticas o patrones solo expresados por las rutinas de los medios de comunicación.

Se inscribieron 113305 candidatos/as a los distintos cargos de elección popular en juego en las elecciones de 2015. Del total general, 41507 (39 \%) eran candidatas. Esto de entrada ya no muestra un desequilibrio respecto de la participación y posterior representatividad del género femenino en las elecciones. Los cargos más relevantes, al menos mediáticamente, las alcaldías y las gobernaciones, es donde el porcentaje de mujeres inscritas es mucho menor. Del total de inscritos/as a estos cargos, solo 14 y $16 \%$, respectivamente, son mujeres.

Este desequilibrio se agudiza aún más cuando se muestra que el cubrimiento mediático del proceso electoral tiene una participación femenina solo de $14 \%$ en el universo de las notas analizadas frente a 86 \% de candidatos hombres que aparecen mucho más en las notas y, por tanto, tienen mayor visibilidad y relevancia frente al electorado.

\section{Figura 6. Género y territorio en el cubrimiento electoral.}

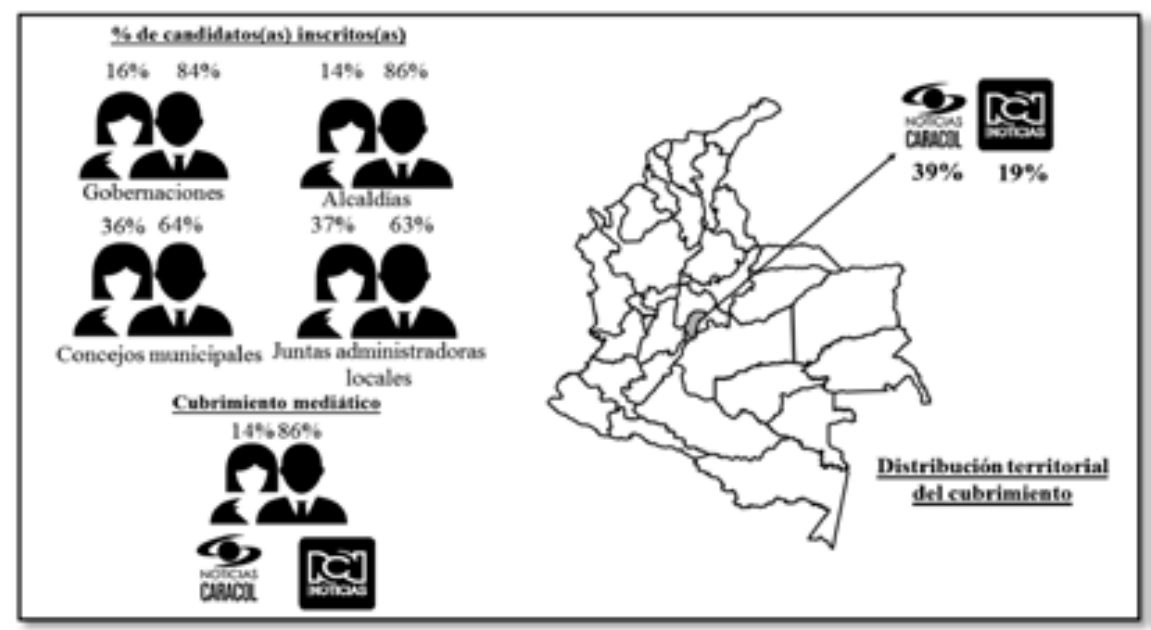

Fuente: elaboración propia

Finalmente, y no menos relevante, se evidencia un fenómeno preocupante de centralismo informativo. El 39 \% de las notas analizadas para Noticias Caracol se enfoca en la campaña a la Alcaldía de Bogotá. En Noticias RCN, no es tan alta esta cifra, pero 
de todos modos 19 \% de las notas tiene esta misma orientación. Esto se ve reflejado en las menciones a candidatos en las que los aspirantes a la Alcaldía de Bogotá son los más referidos por ambos medios.

Tabla 3. Quince candidatos más mencionados en los noticieros

\begin{tabular}{|c|c|c|c|}
\hline \multicolumn{2}{|l|}{ Noticias caracol } & \multicolumn{2}{|l|}{ Noticias RCN } \\
\hline Enrique Peñalosa Londoño & 17 & Enrique Peñalosa Londoño & 12 \\
\hline Rafael Pardo Rueda & 15 & Clara Eugenia López Obregón & 9 \\
\hline Clara Eugenia López Obregón & 14 & Rafael Pardo Rueda & 7 \\
\hline Francisco Santos Calderón & 13 & Francisco Santos Calderón & 7 \\
\hline Federico Andrés Gutiérrez Zuluaga & 6 & Federico Andrés Gutiérrez Zuluaga & 7 \\
\hline Norman Maurice Armitage Cadavid & 5 & Gabriel Jaime Rico Betancur & 5 \\
\hline Gabriel Jaime Rico Betancur & 4 & Juan Carlos Roberto Vélez Uribe & 4 \\
\hline Fabio Alonso Salazar Jaramillo & 4 & Carlos Vicente de Roux Rengifo & 3 \\
\hline Alejandro Char Chaljub & 4 & María Mercedes Maldonado Copello & 3 \\
\hline Jhan Carlos Alvernia Vergel & 3 & Fabio Alonso Salazar Jaramillo & 3 \\
\hline Rafael Segundo Sánchez Anillo & 3 & Wilson Arias & 3 \\
\hline María Mercedes Maldonado & 3 & Fernando Rivera Saraza & 3 \\
\hline Carlos Vicente de Roux Rengifo & 3 & Wilmar Orlando Barbosa Rozo & 3 \\
\hline Sergio Isnardo Muñoz Villarreal & 3 & Ricardo Arias Mora & 3 \\
\hline Rodolfo Hernández Suárez & 3 & Juan Carlos Vélez Arboleda & 2 \\
\hline
\end{tabular}

Fuente: elaboración propia

\section{Análisis y recomendaciones}

Las elecciones locales de 2015 en Colombia marcaron un escenario interesante para el análisis por distintas razones. Por un lado, la aparición, por primera vez en este tipo de elección, del partido Centro Democrático del expresidente Álvaro Uribe marcaba un espacio de competencia y fragmentación electoral sin precedentes en los procesos electorales del país. A esto se le suma el alto grado de polarización política que vivía, y aún vive, el país en torno al proceso de paz con las Fuerzas Armadas Revolucionarias de Colombia, que inevitablemente permeó los discursos y las estrategias, sobre todo de los sectores más activos frente a este tema en el ámbito nacional. Estaba en juego la continuidad o recomposición de las fuerzas políticas de las regiones y los municipios del país, dentro del respaldo o no a dicho proceso de paz, y en general la elección se planteó, desde la oposición, como un referendo a la gestión del presidente Juan Manuel Santos, y desde el Gobierno, como el escenario ideal para construir un respaldo electoral que garantizara la presencia de gobernantes “afines” a la paz en las regiones.

En las ciudades, como Bogotá, Medellín, Cali y Barranquilla, estaban en juego proyectos políticos hegemónicos, unos más consistentes que otros, que en algunos 
casos se veían fuertemente cuestionados y en otros buscaban la refrendación ciudadana para seguir en el poder.

En este escenario, se debe contextualizar el análisis del cubrimiento mediático a partir de los hallazgos de la observación y el monitoreo a Noticias RCN y Noticias Caracol. Desde una perspectiva general, se han de mencionar algunos resultados que deben llamar a la reflexión, ya que evidencian prácticas problemáticas para el proceso informativo de formación de opinión pública y la libertad informativa a la hora de tomar decisiones por parte de los ciudadanos.

\section{Las elecciones como una sucesión de episodios: la política anecdótica}

Después de analizar más de doscientas notas se evidencia un predominio del frame episódico sobre el frame temático en el cubrimiento electoral. La política electoral llevada a través de los lentes de Noticias RCN y Noticias Caracol se mueve por los criterios del infoentretenimiento y la personalización de la política. Lo interesante, en esta oportunidad, es que la alta participación de la sociedad civil debido a la lógica del cubrimiento mediático que implica la presencia física del periodista en el terreno lleva a que los issues se personalicen en experiencias y problemáticas ciudadanas que dejan a los políticos en un segundo plano. El frame temático es escaso en el cubrimiento y evidencia un mayor interés por un cubrimiento superficial que da la sensación de presencia en todo el territorio, pero que en realidad no está aportando elementos de juicio para la toma de decisiones de los ciudadanos en las elecciones.

\section{La política de hombres y para hombres}

Como bien se mencionaba, para analizar el lugar de la mujer en el escenario electoral, no basta con quedarse con su presencia mediática. Tal presencia, en este caso, más se ve como ausencia; en parte, es el resultado de elementos estructurales del sistema político y la cultura política colombiana. El 39 \% de candidatos/as inscritos/as eran mujeres y solo tuvieron una presencia de $14 \%$ en las notas emitidas por ambos noticieros. Más allá de la explicación “estadística”, es necesario dejar, al menos para la reflexión, planteados interrogantes frente a la baja exposición mediática de mujeres candidatas en los medios. Esto podría deberse a bajos índices de respaldo de sus propios partidos, a prejuicios culturales que se ven reflejados en las pautas de cubrimiento mediático, o, incluso, a la desconfianza que puede generar en un electorado estructuralmente machista, aun cuando de manera proporcional hay más mujeres que hombres, del rol político de la mujer, sobre todo en el cuestionamiento de su capacidad de liderazgo y sus competencias para la Administración pública.

Esta problemática también debe analizarse desde la misma cultura participativa de las mujeres en las regiones para tratar de entender si, como podría pasar, no hay estímulos 
o interés de estas para la participación política institucionalizada, o si, por el contrario, la mujer sí participa, pero en espacios políticos que no tienen un carácter partidista, como movimientos sociales, iniciativas ciudadanas, espacios comunitarios, entre otros.

\section{Importa más el centro}

Otro aspecto que debe analizarse es la tendencia, que aún perdura en los medios nacionales, de reducir, en una alta proporción, las elecciones locales a la disputa por la Alcaldía de las principales ciudades, más específicamente la de Bogotá. A pesar de los esfuerzos, destacables, de los medios por descentralizar el cubrimiento electoral a través de iniciativas como recorridos o caravanas democráticas, el cubrimiento sigue padeciendo de altos niveles de centralismo informativo.

Las regiones y los municipios del país solo obtienen atención en el cubrimiento cuando encajan dentro de los parámetros de infoentretenimiento, especialmente cuando los episodios que "narran" la realidad política de estos lugares giran en torno a escándalos, prácticas corruptas, perturbaciones de orden público o hechos curiosos

Este centralismo se presenta también en las regiones. Después de los candidatos a la Alcaldía de Bogotá, los candidatos más mencionados son los que aspiran a las alcaldías de las capitales de los principales departamentos. Esto no refleja la verdadera composición de la sociedad colombiana y da una falsa imagen del país político en el que vivimos.

Todavía persiste en buena medida una centralización del cubrimiento sobre las elecciones de Bogotá. No obstante, cabe destacar que ambos canales, dentro de sus secciones especiales, implementaron recorridos a lo largo del país que generaron un contexto mínimo sobre las principales ciudades y departamentos, hecho que debe destacarse como positivo.

\section{Cuanto más cerca menos me informan}

Otro elemento interesante, y preocupante a la vez, que incide en agudizar aún más otros escenarios, como el desequilibrio de género, tiene que ver con la nula existencia en el cubrimiento mediático de los cargos de representación popular (concejos municipales y juntas administradoras locales). Es paradójico, o al menos, inquietante, que quienes son las autoridades más cercanas a la cotidianidad de los ciudadanos, prácticamente, no existan para los medios de comunicación.

El centralismo informativo, orientado hacia Bogotá donde no se elige gobernador, hace que esta figura también pase a un segundo plano, salvo en los departamentos más importantes, o en casos donde existan candidatos que posean las características mediáticas que los hagan dignos de que los grandes medios posen sus ojos sobre ellos.

Si volvemos sobre los datos de género, se incrementa la preocupación al ver la correlación negativa que existe entre una mayor participación femenina en las elecciones a 
Concejo y juntas administradoras locales y su baja visibilidad, por no decir inexistente, en los medios analizados. Podría concluirse que los espacios de participación política femenina son precisamente los que menos atención despiertan en los medios, mientras que gobernaciones y alcaldías se ponen en escena como una contienda de hombres por el alto poder de sus departamentos y ciudades. Esto tiene un efecto sobre las estrategias de campaña de las pocas mujeres que logran romper el cerco y participar en estos espacios que deben "masculinizar" su discurso, apariencia e imagen para ser tomadas en serio por los medios de comunicación.

\section{Más gente, menos políticos}

Se evidencia, en parte gracias al enfoque del cubrimiento en terreno del proceso, un aumento desbordado de la participación ciudadana en detrimento de los políticos en el cubrimiento mediático. Esto no es exclusivo del cubrimiento mediático y también se da en la publicidad política donde el candidato es desplazado por el ciudadano del común como emisor de los mensajes. La ciudadanía aparece como una fuente informativa. El problema de fondo es que no se aprovecha al ciudadano como un elemento de contexto político, sino como una herramienta de denuncia o de corroboración de escándalos o episodios.

\section{La atención llega con el medio y se va con él}

La misma dinámica mencionada genera que la visibilidad que se consigue para un municipio o una comunidad sea tan efímera como la presencia del medio. Hasta cierto punto podría hablarse más que de una intención por informar a fondo de una instrumentalización informativa según episodios "curiosos" o escándalos políticos.

Por la misma heterogeneidad regional, es muy difícil que las agendas de los medios nacionales puedan cubrir todos los temas y todos los actores de la política local y regional, por lo cual, si bien se destaca el esfuerzo por descentralizar el cubrimiento, este peca por superficial y poco contextualizado. En muchos casos, la atención dura lo que se extienda en el tiempo la presencia del medio en el lugar.

El cubrimiento local en vivo exacerba el criterio de coyunturalidad, lo cual no permite que sean visibles los temas estructurales que aquejan a los municipios.

\section{Las agendas: diferencias que evidencian intereses}

En el caso de Caracol, el énfasis apunta más al proceso y las problemáticas políticas, jurídicas y sociales generales relacionadas. El énfasis se da sobre aspectos procedimentales del proceso electoral, lo cual impide, en cierta medida, la tentación del sesgo político o partidista.

El énfasis de RCN muestra una mayor orientación hacia problemas de orden público, los problemas de la economía nacional y los temas de infraestructura, que pueden estar 
alineadas con sectores políticos específicos. Esto se ve en el predominio de fuentes del partido Centro Democrático en los recorridos regionales.

\section{La paz en las regiones no da votos}

Un hecho que no debe pasar desapercibido es la mínima presencia del tema proceso de paz en las notas analizadas. Todo parece indicar que las lógicas y las agendas de la política local se mueven bajo otros parámetros y a otro ritmo. Es interesante cómo el tema central de la agenda política nacional brilla por su ausencia en la agenda mediática de las elecciones locales. En este punto, las expectativas ciudadanas frente a sus dirigentes se orientan más a la solución de problemáticas concretas que para el ciudadano parecen no estar conectadas con lo que se está viviendo en La Habana.

Se debe mencionar, para el equilibrio, que no se le puede exigir a los medios nacionales, más allá de su alcance, que estén en 100 \% del territorio y que incorporen dentro de su agenda setting las preocupaciones de todos los colombianos. Es valorable la intención de descentralizar el cubrimiento e incorporar a la ciudadanía como un actor activo del proceso.

Sin embargo, y a modo de recomendaciones finales, se sugiere empezar a pensar en cómo tratar en el futuro el cubrimiento de este tipo de fenómenos políticos.

Los medios deben comprender su responsabilidad social como principales fuentes informativas del país, especialmente los noticieros de los canales más vistos. Su compromiso con la democracia colombiana está atravesado por una función pedagógica más fuerte que permita sacar de la opacidad los cargos de elección municipal donde se presentan los mayores niveles de desinterés y desconocimiento, como lo son los concejos municipales y las juntas administradoras locales, no solo presentando a los candidatos y sus propuestas, sino haciendo comprender a la ciudadanía la razón de ser e importancia de estos cargos. Igual que en la cuestión de género, los medios pueden estar contribuyendo a un ciclo de opacidad informativa que hace que los ciudadanos no participen de estos espacios al no conocer absolutamente nada de ellos o solo tener noción de estos a partir de escándalos, como el carrusel de la contratación en Bogotá.

Los medios deben seguir avanzando en formatos que permitan un mayor equilibrio informativo y pluralismo político. El escenario de posconflicto supone un sistema político aún más diverso política e ideológicamente. Los medios tienen la responsabilidad de legitimar y visibilizar las distintas opciones existentes y nuevas que aparecerán en el sistema político y permitir a los ciudadanos conocer sus posturas y decidir libremente.

Parte de la sostenibilidad del sistema democrático en el futuro radica en la fortaleza de sus instituciones y procedimientos sobre todo en el ámbito de lo local. Es por eso tan importante el papel que cumplan los medios en los procesos electorales como actores informativos que permitan fortalecer la democracia antes que obstaculizarla. 


\section{Referencias}

Benjamin, D. (2007). FrameByte Episodic vs. Thematic Stories. Recuperado de http:// www.frameworksinstitute.org/assets/files/framebytes/framebyte_thematic.pdf

Berrocal, S. (2004). Una aproximación a la nueva retórica del líder político televisivo: acciones, cualidades y discurso. Doxa Comunicación, 2, 53-67.

Boix, C. y Stokes, S. (eds.) (2009). Oxford handbook of comparative politics. OUP Oxford.

Craig, R. (2000). Expectations and elections: How television defines campaign news. Critical Studies in Media Communication, 17(1), 28-44.

Dader García, J. L. (1998). La absorción mediática de la política: personalización de la política. En J. L. Dader García (ed.), Tratado de comunicación política (pp. 114-140). Madrid: CERSA.

Gibson, R. y Römmele, A. (2001). Changing campaign communications: A party-centered theory of professionalized campaigning. The Harvard International Journal of Press/Politics, 6(4), 31-43.

Goofman, E. (1986). Frame analysis: An essay on the organization of experience. Nueva York: Northeastern University.

Grabe, E. (2009). Image bite politics: news and the visual framing of elections. Oxford: Oxford Universiy Press.

Gulati, G., Just, M. y Crigler, A. (2004). News coverage of political campaigns. En N. K. Denzin y Y. S. Lincoln (eds.), Handbook of political communication research (pp. 237-256). Londres: LEA.

Holtz-Bacha, C. (2002). Professionalization of political communication: The case of the 1998 SPD campaign. Journal of Political Marketing, 1(4), 23-37.

Iyengar, S. (1994). Is anyone responsible? How television frames political issues. Chicago: University of Chicago Press.

Johnson-Cartee, K. S. (2004). News narratives and news framing: Constructing political reality. Lanham: Rowman \& Littlefield Publishers.

Kaid, L. L. (ed.). (2004). Handbook of political communication research. Routledge.

Kamber, V. (2003). Poison politics: Are negative campaigns destroying democracy? Basic Books.

Lange, B. y Ward, D. (2004). The media and elections: A handbook and comparative study. Londres: LEA. 
Lilleker, D. G. (2006). Key concepts in political communication. Londres: Sage.

Mancini, P. y Swanson, D. (1996). Politics, media, and modern democracy: Introduction. En D. L. Swanson y P. Mancini (eds.), Politics, media, and modern democracy: An international study of innovations in electoral campaigning and their consequences (pp. 1-26). Londres: Praeger.

Martínez Pandiani, G. (2014). El impacto de la televisión en la comunicación política moderna. Signos Universitarios, 25(1), 69-88.

Scheufele, D. A. y Tewksbury, D. (2007). Framing, agenda setting, and priming: The evolution of three media effects models. Journal of Communication, 57(1), 9-20.

Schmitt-Beck, R. (2009). New modes of campaigning. En R. Dalton y H. Klingerman, Oxford handbook of political behavior (pp. 744-764). Oxford: Oxford University Press.

Semetkho, H. (2007). Political communication. En R. Dalton y H. Klingerman, Oxford handbook of political behavior (pp. 123-124). Oxford: Oxford University Press.

Strömbäck, J. (2008). Political marketing and professionalized campaigning: A conceptual analysis. Journal of Political Marketing, 6(2-3), 49-67.

Strömbäck, J. y Kaid, L. L. (eds.) (2008). The handbook of election news coverage around the world. Nueva York: Routledge.

WVS Database (2014). http://www.worldvaluessurvey.org/wvs.jsp 